\title{
Drug-drug interactions and potentially inappropriate medications among elderly outpatients
}

\author{
Atrianfar Fatemeh ${ }^{1}$, Rezaei Fatemeh², Heidari Kazem², \\ Kargar Mona ${ }^{\circledR 2}$, Javadi Mohammad Reza ${ }^{2}$, Gholami Kheirollah ${ }^{2}$ \\ ${ }^{1}$ Faculty of pharmacy, Tehran University of Medical Sciences, Tehran, Iran, ${ }^{2}$ Research \\ Center for Rational Use of Drugs, Tehran University of Medical Sciences, Tehran, Iran
}

\begin{abstract}
The high prevalence of concomitant chronic illnesses and the resulting higher number of medications in the elderly population increase the risk of adverse drug reactions due to drug-drug interactions (DDIs) and potentially inappropriate medications (PIMs). Therefore, the aim of this study was to investigate the prevalence and factors associated with DDIs and PIMs in outpatient geriatrics. In this cross-sectional study, 1512 prescriptions belonging to patients aged $\geq 65$ years from five public pharmacies in Tehran were evaluated. Clinically relevant $(\mathrm{C}, \mathrm{D}$, and $\mathrm{X}$ ) and significant DDIs (D and $\mathrm{X})$ were documented according to the Lexicomp ${ }^{\circledR}$. Additionally, Zhan criteria were used to detect PIMs. At least one clinically relevant DDI was detected in $61.7 \%$ of the prescriptions containing $\geq 2$ medications. The largest percentage of prescriptions with DDIs was prescribed by cardiologists (74.3\%). The number of medications in prescriptions and the specialty of the prescriber significantly affected both clinically relevant and significant DDIs in a logistic regression model. At least one PIM was identified in $16.3 \%$ of the prescriptions. General practitioners (GPs) were the largest prescribers of PIMs. The mean number of medications was significantly higher in prescriptions with PIMs. In conclusion, clinically relevant DDIs are frequent in the elderly. In terms of PIMs, more attention should be paid to the education of GPs.
\end{abstract}

Keywords: Elderly. Zhan criteria. Drug Interactions. Potentially Inappropriate Medication.

\section{INTRODUCTION}

The population of geriatrics is increasing rapidly worldwide. It is estimated that the global elderly population will increase from $12 \%$ of the total population in 2015 to $22 \%$ in 2050 (World Health Organization, 2017). Each of these populations uses about 14 to 18 prescription drugs each year (Steele et al., 2016), which can be due to several chronic diseases (Bazargan et al., 2016). In other words, the higher prevalence of chronic illnesses in the elderly results in using multiple drugs concomitantly or polypharmacy (Rosa et al., 2016, Salwe, Kalyansundaram, Bahurupi, 2016, Sánchez-Fidalgo et al., 2017). Although these multiple medications are commonly administered to

*Correspondence: M. Kargar. Research Center for Rational Use of Drugs. Tehran University of Medical Sciences, Tehran, Iran. 4th floor, No: 92, South Kheradmand Junction, Karimkhan-e-zand Ave, Tehran, Iran. Telephone: +98 21 888-14-157. Postal Code: 1585913111. ORCID: 00000002-2572-4991. Email address: mkargar@razi.tums.ac.ir achieve a better therapeutic response, they can increase the risk of adverse drug reactions (ADRs) (Basnet et al., 2016; Scondotto et al., 2018), drug-drug interactions (DDIs) (Basnet et al., 2016; Gören et al., 2017; Hersh, Beldowski, Hajjar, 2017; Sánchez-Fidalgo et al., 2017) and medication costs (Basnet et al., 2016).

DDI is defined as an alteration in the effects of one medication when it is administered concurrently with another (Salwe, Kalyansundaram, Bahurupi, 2016; Teka et al., 2016). Two main categories of DDIs include pharmacokinetic and pharmacodynamic interactions. Pharmacokinetic interactions can lead to a change in the blood level of a medication due to alterations in the pharmacokinetic properties that eventually result in changes in clinical effects. Pharmacodynamic drug interactions are changes in the anticipated effects of a medicine in the form of antagonism and synergism (Fadare et al., 2016). 
Another important factor that plays a major role in the increased incidence of DDIs is visiting elderly patients by different physicians. Even it has been shown that $37 \%$ of the elderly patients' medicines are prescribed by physicians other than their primary doctors (Welker, Mycyk, 2016). Inattention to the relevance of the interactions and the poor knowledge of the prescribers may also result in DDIs (Nabovati et al., 2014).

Approximately 5.6-63\% of the drug-related problems can be attributed to DDIs. Additionally, $46 \%$ of the elderly patients experience at least one DDI (Juárez-Cedillo et al., 1865), which is responsible for 2-3\% of hospital admissions (Nabovati et al., 2016). The incidence of ADRs related to DDIs is significantly high in the elderly, most of which are clinically important (Obreli-Neto et al., 2012). These ADRs can eventually increase the cost of care, morbidity, and hospital stay (Fadare et al., 2016). Unfortunately, electronic prescription, which can reduce DDIs, is not widely available in Iran. Additionally, based on a systematic review, DDIs have a high prevalence (Nabovati et al., 2017).

Another important issue in the pharmacotherapy of geriatrics is potentially inappropriate medications (PIMs). PIMs can be defined as medicines or classes of medicines that should be avoided in patients aged $\geq 65$ years because they are ineffective or predispose patients to unnecessary high risks (Salwe, Kalyansundaram, Bahurupi, 2016) and safer alternatives are available for them (Novaes et al., 2017; Salwe, Kalyansundaram, Bahurupi, 2016).

To evaluate the medication appropriateness for the elderly population, one way is to use explicit criteria, which in fact serve as prescribing indicators for geriatrics in both research and practice (Steinman et al., 2009). An example is the Zhan criteria, which are based on the 1997 version of the Beers criteria (Buck et al., 2009). These criteria include a list of 33 inappropriate medications that are classified into three main categories as "always avoid", "rarely appropriate", and "some indications" (Barnett et al., 2006; Williams et al., 2010).

Due to the importance of DDIs and PIMs in the pharmacotherapy of geriatric patients, the purpose of the present study was to determine the prevalence of DDIs and PIMs in prescriptions of elderly outpatients in Tehran.

\section{MATERIAL AND METHODS}

\section{Study design and sampling}

This cross-sectional study was conducted in five pharmacies affiliated with the Faculty of Pharmacy of Tehran University of Medical Sciences (TUMS). The study was part of a research project conducted to evaluate different medication-related issues in the elderly (Zarif-Yeganeh et al., 2019; Kargar et al., 2019). In this study, insurance prescriptions for patients aged $\geq 65$ years were included. The study was performed from January to March 2014. The insurance organizations included were the Social Security Insurance Organization (SSIO), Medical Services Insurance Organization (MSIO) (currently known as Health Care Insurance), Armed Forces Medical Services Insurance Organization (AFMSIO), and Rural Insurance. The number of prescriptions from these insurance organizations was determined based on the population under their coverage. The study was approved by the Ethics Committee of TUMS.

\section{Assessment of DDIs}

DDIs in the prescriptions were investigated using the UpToDate ${ }^{\circledR}$ online DDI checker (available online from the TUMS website in February 2015). The LexiInteract Module is a database that is incorporated into the UpToDate ${ }^{\circledR}$ (Reis, Cassiani, 2010) and is generally used in clinical settings (Lao et al., 2013) for detection of DDIs. In this database, the clinical relevance of DDIs is categorized in a system as A, B, C, D, and X. In case of an interaction in the $\mathrm{C}$ category, drug therapy needs to be monitored. Treatment modification is needed for category $\mathrm{D}$ interactions and drug combinations with category $\mathrm{X}$ interactions must be avoided (Lexicomp ${ }^{\circledR}$ Online $^{\mathrm{TM}}$ user guide, 2015). In the current study, clinically relevant DDIs of C, D, and X were considered. Additionally, significant DDIs were defined as D and X categories, which were analyzed separately. To evaluate the DDIs in prescriptions, medications in each prescription were imported into a Microsoft Excel file. Then, the presence of DDIs and the level of interactions as well as the number of interactions in each prescription were evaluated and documented. To double check the severity of the category $\mathrm{X}$ interactions, they were further investigated in "Drug Interaction Facts" published in 2014.

\section{Assessment of PIMs}

The items in prescriptions were matched against the Zhan criteria to detect PIMs. The classes of PIMs in Zhan criteria were determined separately and the number of PIMs was reported in a table. 


\section{Statistical analysis}

Descriptive statistics were applied including mean (SD) for quantitative variables and frequency (percentage) for qualitative variables. The mean number of DDIs/PIMs in the prescriptions of prescribers with different educational levels and specialties was compared using the KruskalWallis test. The Spearman correlation coefficient was also calculated to investigate the correlations between variables. Additionally, logistic regression was used to investigate the role of different factors in receiving clinically relevant and significant DDIs.

\section{RESULT}

In this study, 1512 prescriptions were included from the pharmacies. The mean (SD) age of the patients was 73.9(6.7) years and $790(52.4 \%)$ patients were men. Nearly one-third of the prescriptions $(474,31.3 \%)$ were prescribed by general practitioners (GPs). Among specialists, internists were the most frequent prescribers with 357 (23.61\%) prescriptions. The mean number of items per prescription (SD) was 3.6(1.9).

\section{Drug-drug interactions}

At least one clinically relevant DDI was noted in $800(52.9 \%)$ prescriptions. However, after including prescriptions with $\geq 2$ drugs, the prevalence of DDI increased to $61.7 \%$. The maximum number of interactions was 31 in one prescription including 10 items. The mean number of interactions per patient was 1.6. Among prescriptions, $44.7 \%$ contained 1 to 5 clinically relevant DDIs. The frequency of prescriptions with different ranges of clinically relevant DDIs is shown in Figure 1.

$\mathrm{C}, \mathrm{D}$, and $\mathrm{X}$ interactions were observed in $735(76.2 \%)$, $182(18.9 \%)$ and $47(4.9 \%)$ prescriptions, respectively. Among prescriptions with DDIs, the most severe DDIs belonged to the C and D category in $578(72.2 \%)$ and $175(21.9 \%)$ prescriptions, respectively.
Totally, 2372 DDIs including 2095 (88.32\%) C, 228 $(9.61 \%) \mathrm{D}$, and $49(2.06 \%) \mathrm{X}$ interactions were documented. At least one DDI was noted in all of the prescriptions with $>7$ medicines (Figure 2).

Among prescriptions by GPs, at least one DDI was noted in $264(55.7 \%)$ prescriptions. The percentage of prescriptions with at least one DDI was significantly lower in prescriptions wrote by medical residents (39.1\%) $(\mathrm{P}=0.026)$ (Table I). Among specialties with $>50$ prescriptions in our sample, a significant difference was found regarding the percentage of DDIs in prescriptions $(\mathrm{P}<0.001)$. The highest percentage of prescriptions with at least one DDI was prescribed by cardiologists (74.3\%) followed by neurologists $(70.1 \%)$ while the lowest belonged to ophthalmologists (16.7\%) (Figure 3).

Losartan $(n=381)$, nitroglycerin $(n=242)$, aspirin $(\mathrm{n}=227)$, amlodipine $(\mathrm{n}=225)$ and metoprolol $(\mathrm{n}=206)$ were the most frequent drugs involved in DDIs. The most frequent paired drug interactions within $\mathrm{C}, \mathrm{D}$ and $\mathrm{X}$ categories are summarized in Table II.

Comparison of the frequency of DDIs between men and women showed that $56 \%$ of women and $50 \%$ of men experienced at least one DDI $(\mathrm{P}=0.02)$. However, this finding needs to be interpreted cautiously since the larger number of DDIs in women's prescriptions was in accordance with a statistically significant higher mean number of medications per prescription in this group ( 3.77 vs. 3.39 in women and men, respectively $\mathrm{P}<0.0001$ ). Additionally, with controlling the number of medications in prescriptions using regression analysis, sex did not independently affect DDIs (Table III).

Logistic regression was applied to evaluate the effect of sex, age, number of medications per prescription, and specialties with the highest and lowest frequency of DDIs (ophthalmology, cardiology, neurology, and orthopedics) on clinically relevant DDIs. The results showed that the number of medications per prescription and specialty (ophthalmology and cardiology) remained significant in the final model (Table III). 


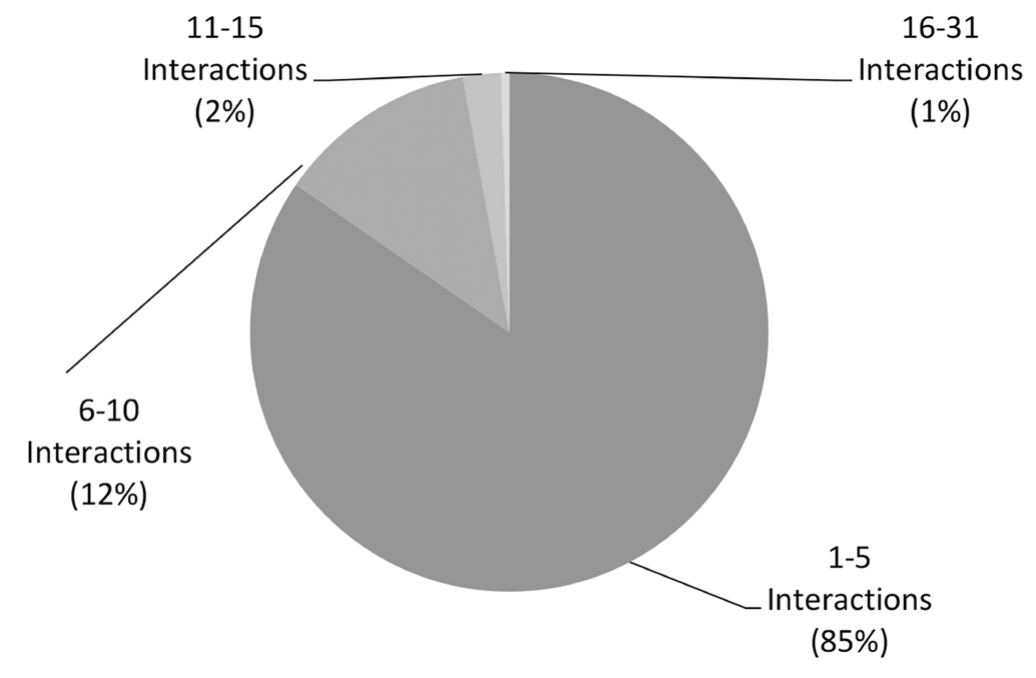

FIGURE 1 - Frequency of different number of clinically relevant Drug- Drug Interactions in prescriptions.

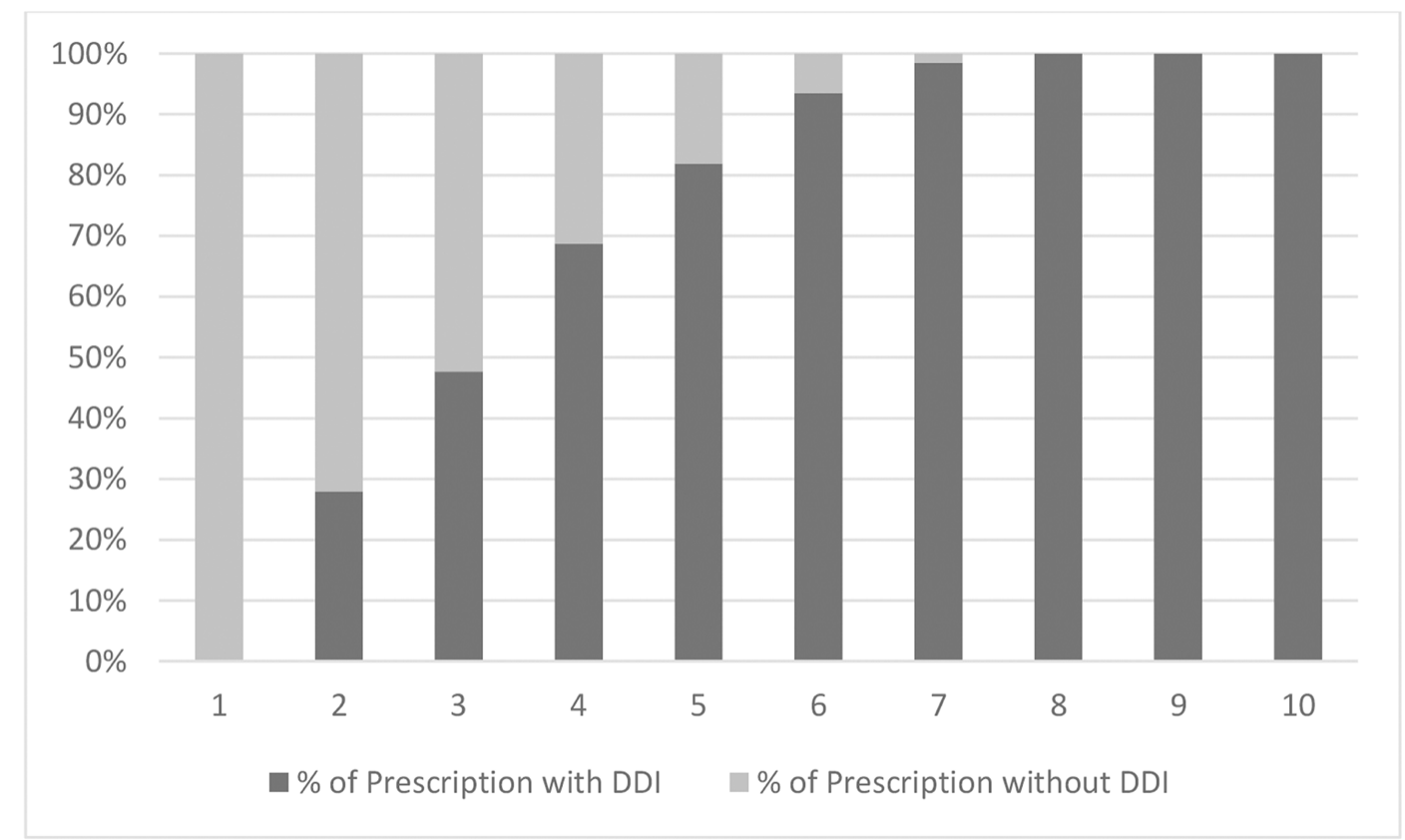

FIGURE 2 - Percentage of clinically relevant Drug- Drug Interaction in prescriptions based on the number of items in prescription. 


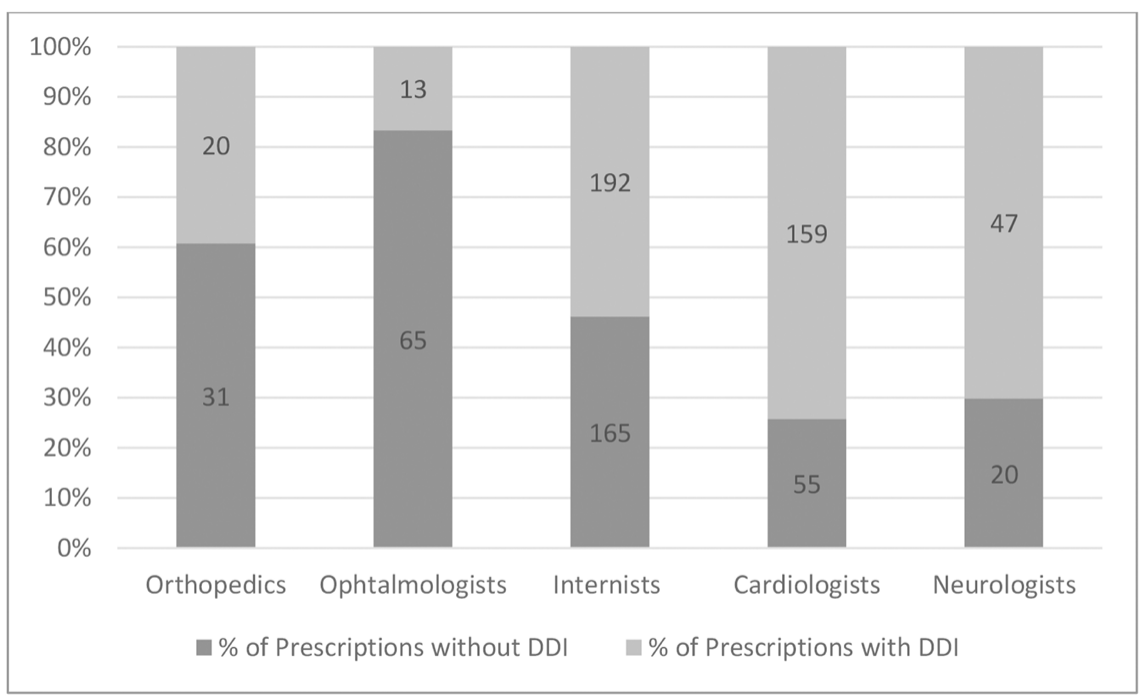

FIGURE 3 - Prevalence of clinically relevant (C, D and X) drug interactions within different specialties with $>50$ prescriptions.

TABLE I - Number of prescriptions of different prescribers and prevalence of drug interaction and potentially inappropriate medications

\begin{tabular}{lcccccc}
\hline Prescribers N (\%) & GPs & Residents & Specialists & Subspecialists & Dentists & Total \\
\hline $\begin{array}{l}\text { Prescriptions with } \\
\text { DDI N (\%) }\end{array}$ & $264(55.7)$ & $45(39.1)$ & $335(54.0)$ & $153(51.7)$ & $3(42.8)$ & $800(100)$ \\
\hline $\begin{array}{l}\text { Prescriptions with } \\
\text { PIM N (\%) }\end{array}$ & $154(32.50)$ & $7(6.10)$ & $66(10.60)$ & $20(6.80)$ & - & $247(16.40)$ \\
\hline \begin{tabular}{l} 
Total N (\%) \\
\hline
\end{tabular} & $474(31.3)$ & $115(7.6)$ & $620(41.0)$ & $296(19.6)$ & $7(0.5)$ & $1512(100)$ \\
\hline
\end{tabular}

GP: General Practitioner, DDI: Drug- Drug Interaction, PIM: Potentially Inappropriate Medication

TABLE II - Frequent drug interactions within C, D and X category and frequency of potentially inappropriate medication in different Zhan categories

\begin{tabular}{lccc}
\hline DDI & Frequency & PIM & Frequency \\
\hline Category C & & Always avoid & Hyoscine \\
& & Dicyclomine & 8 \\
Losartan-Nitroglycerine & 59 & Phenobarbital & 8 \\
Nitroglycerine-Metoprolol & 42 & Belladonna & 3 \\
Metformin-Glibenclmide & 42 & & 2 \\
& & & \\
\hline
\end{tabular}


TABLE II - Frequent drug interactions within C, D and X category and frequency of potentially inappropriate medication in different Zhan categories

\begin{tabular}{lccc}
\hline DDI & Frequency & PIM & Frequency \\
\hline Category D & & Rarely appropriate $^{2}$ & \\
& & Chlordiazepoxide & 29 \\
Pantoprazole-Clopidogrel & 11 & Clidinium C & 25 \\
Diltiazem-Atorvastatin & 9 & Methocarbamol & 15 \\
Alendronate-Calcium D & 8 & Diazepam & 8 \\
\hline
\end{tabular}

\section{Category X}

Prazosin-Tamsulosin

Celecoxib-Piroxicam gel

Vitamin D-Multivitamin

\section{Frequent Interactions}

Losartan-Nitroglycerine

Losartan-Amlodipin

Losartan-Metoprolol

Nitroglycerine-Metoprolol

Metformin-Glibenclamide
59

52

50

42

42

\section{Some indications ${ }^{3}$}

Chlorpheniramine $^{4} \quad 86$

Diphenhydramine $^{5} \quad 40$

Dipyridamol 17

Indomethacin 12

Hydroxyzine 9

Oxybutynin 7

Amitriptyline 5

Cyproheptadine 4

Doxepine 4

Methyldopa 1

Promethazine 1

Ticlopidine 1

DDI: Drug- Drug Interaction, PIM: Potentially Inappropriate Medication

${ }^{1}$ Prescriptions with Categoryl N (\%): One PIM: 15(1.0), Two PIMs: 3(0.2), Total: 18(1.2)

${ }^{2}$ Prescriptions with Category2 N (\%): One PIM: 67(4.4), Two PIMs: 5(0.3), Total: 72(4.7)

${ }^{3}$ Prescriptions with Category 3 N (\%): One PIM: 147(9.7), Two PIMs: 20(1.3), Total: 167(11.0)

${ }^{4}$ Medication containing Chlorphenirmine: Adult $\operatorname{cold}^{\circledR}(\mathrm{N}=59)$, Antihistamine decongestant $(\mathrm{N}=2)$, Expectorant $(\mathrm{N}=20)$ and Chlorpheniramin $(\mathrm{N}=5)$.

${ }^{5}$ Medication containing Diphenhydramin were Cold $\operatorname{stop}^{\circledR}(\mathrm{N}=6), \operatorname{Coldax}^{\circledR}(\mathrm{N}=8)$, Dimenhydrinat $(\mathrm{N}=3)$ and Diphenhydramin $(\mathrm{N}=23)$.

TABLE III - Final model of multivariate logistic regression analysis to identify the independent factors associated with clinically relevant DDIs

\begin{tabular}{lcccc}
\hline Characteristic & B & S.E. & Exp(B) & Significance \\
\hline Number of items in prescriptions & 1.013 & 0.054 & 2.755 & 0.000 \\
\hline Prescriptions by ophthalmologists & -1.023 & 0.351 & 0.359 & 0.004 \\
\hline Prescription by cardiologists & 0.726 & 0.212 & 2.066 & 0.001 \\
\hline Prescriptions by neurologists & 0.807 & 0.336 & 2.240 & 0.016 \\
\hline Constant & -3.349 & 0.188 & 0.035 & 0.000 \\
\hline
\end{tabular}




\section{Significant DDIs}

Significant DDIs were found in $14.61 \%$ of the prescriptions and constituted $11.69 \%$ of the interactions. Similar to clinically relevant DDIs, the frequency of significant DDIs differed significantly among different specialties with $>50$ prescriptions $(\mathrm{P}<0.001)$. Prescriptions by neurologists $(29.9 \%)$ followed by orthopedics (21.6\%) included the largest and prescriptions by ophthalmologists (7.7\%) had the smallest number of significant DDIs.
Logistic regression was used to evaluate the effect of sex, age, the number of medications per prescription and the specialties with the highest and lowest DDIs (ophthalmology, cardiology, neurology, and orthopedics) on significant DDIs. The results showed that the number of medications per prescription, age, and specialty (neurology and orthopedic) remained significant in the final model (Table IV).

TABLE IV - Final model of multivariate logistic regression analysis to identify the independent factors associated with significant DDIs

\begin{tabular}{lllll}
\hline Characteristic & B & S.E. & Exp (B) & Significance \\
\hline Age & 0.022 & 0.012 & 1.022 & 0.065 \\
\hline Number of items per prescriptions & 0.494 & 0.042 & 1.639 & 0.000 \\
\hline Prescriptions by neurologists & 0.808 & 0.325 & 2.243 & 0.013 \\
\hline Prescriptions by orthopedics & 0.880 & 0.376 & 2.410 & 0.019 \\
\hline Constant & -5.529 & 0.910 & 0.004 & 0.000 \\
\hline
\end{tabular}

\section{Checking the severity of $X$ interactions}

Interactions with $\mathrm{X}$ severity were noted in 47 prescriptions. More than one-third of these interactions were due to prescribing duplications (e.g. interaction between prazosin + tamsulosin or celecoxib + piroxicam) or prescribing the same pharmacologic agent as one of the ingredients of another medication.

It should be noted that in "Drug Interaction Facts", drug duplications are not included in DDIs. Other cases of DDIs reported in the Lexicamp ${ }^{\circledR}$ were similar to the "Drug Interaction Facts" in terms of severity except for two instances: the interaction between tetrabenazine and tranylcypromine, which is reported to be of moderate severity and rapid onset in the "Drug Interaction Facts", and the interaction between selegiline and cyproheptadine, which is reported to be of moderate severity, delayed onset and poor probability of occurrence in the "Drug Interaction Facts".

\section{PIMs}

It was noted that at least one medication included in the Zhan criteria was present in $247(16.3 \%)$ prescriptions. One PIM was detected in 209 (84.61\%) and two PIMs were found in $38(15.38 \%)$ prescriptions. Among all medications in the prescriptions, 285(5.2\%) were PIMs, including 21 (7.37\%), 77 (27.01\%), and 187 (65.61\%) medications in the first (always avoid), second (rarely appropriate), and third (some indications) categories of the Zhan criteria, respectively (Table II).

No significant correlation was found between the number of PIMs in prescriptions and age $(\mathrm{r}=-0.025$, $\mathrm{P}=0.34$ ). Additionally, comparison of the mean age of patients with and without PIMs in their prescriptions did not reveal any significant differences $(\mathrm{P}=0.351)$. The presence of PIMs was similar in men and women (17.4\% vs. $15.4 \%$ respectively, $\mathrm{P}=0.30$ ). However, the presence of PIMs significantly varied between the prescriptions of different 
prescribers $(\mathrm{P}<0.001)$ and GPs were the largest prescribers of PIMs. None of the prescriptions by dentists contained PIMs (Table I). It was found that the mean number of medications per prescriptions containing at least one PIM was significantly higher compared to prescriptions without a PIM (4.3 \pm 1.7 vs., $3.4 \pm 1.9$ respectively $)(\mathrm{P}<0.001)$. Among prescriptions by specialists, "always avoid" medications were found in 4 prescriptions containing one PIM [two internists, one psychiatrist and one neurologist] and in one prescription with 2 PIMs [a pediatrician]. "Rarely appropriate" medications were found in 34 prescriptions by specialists that contained one PIM, in which internists $(n=10)$ and cardiologists $(n=6)$ had a large share. Only one prescription by a neurologist contained 2 PIMs of this category. Medications with "some indications" were detected in 53 prescriptions by specialists, of which 24 were written by internists. Only 4 prescriptions contained 2 drugs of this category ( 2 internists, one psychiatrist and one infectious disease specialist).

\section{DISCUSSION}

This study was conducted to determine the prevalence and factors associated with DDIs and PIMs in a sample of elderly outpatient prescriptions. It was found that $61.7 \%$ of the patients who received at least two medications experienced a DDI.

The frequency of DDIs varies in several studies mainly due to differences in the study setting, patient selection, severity of DDIs, and the tools used to detect them (Secoli et al., 2010; Tulner et al., 2008). For example, a clinical review found the prevalence of potential DDIs in the elderly population ranged from $1.5 \%$ to $47.4 \%$ (Gnjidic, Johnell, 2013). In a study in Croatia in elderly patients discharged from the internal medicine clinic with two or more medications, the prevalence of DDIs based on the Lexi-Interact software was $85.6 \%$ (Marusic et al., 2013). Compared to the latter, the current study reported a lower prevalence despite similarities in methods.

There are also methodological variations among the studies previously conducted in Iran. For example, in a study on elderly prescriptions in six cities of East Azerbaijan Province, the Swedish classification system was used to assess the clinically relevant DDIs, and the prevalence of DDIs was found to be $14 \%$ (Ghadimi, Esmaily, Wahlstrom, 2011). In another study in Isfahan on elderly prescriptions using the Micromedex, DDIs were identified in $10 \%$ of the patients (Azoulay et al., 2005). However, none of the above studies included prescriptions by specialists and the tools used to detect DDIs were different from the current study.

In terms of significant interactions, a recent study on health claims data in Slovenia showed a prevalence of $28.1 \%$ for DDIs with D and X severity based on the Lexi-Interact in elderly outpatients (Jazbar et al., 2017), which is higher than our results (14.61\%). However, in a study of the elderly in primary health care using the LexiInteract in Turkey, $\mathrm{D}$ and $\mathrm{X}$ interactions accounted for $10.96 \%$ of the sum of C, D, and X interactions (Gören et al., 2017), which is quite similar to our finding (11.69\%). It was noted that the $\mathrm{C}$ interactions were the most prevalent DDIs reported in $76.2 \%$ of our prescriptions. This finding was similar to other studies in the general population (Dirin et al., 2014; Jazbar et al., 2017).

Regarding the role of gender, considerable results were achieved. Despite a significantly higher prevalence of DDI in women, when the number of medications was controlled in regression analysis, the difference was no more significant. It seems that a consensus has not been achieved regarding the role of gender in this issue. In some previous studies of the elderly outpatients that reported a significantly higher DDI in women, the mean number of medications was not compared between genders nor was controlled (Gören et al., 2017). This was similar to a study in which higher clinically important potential DDIs were detected in the elderly women in the primary health system (Neto et al., 2012).

However, opposite findings have also been reported indicating a lower probability of potentially serious DDIs in women after adjustment for age and number of dispensed drugs in the elderly (Johnell, Klarin, 2007). Moreover, in a study conducted in the Chinese elderly living in nursing homes, gender was not found to be an independent factor associated with potential DDIs (Lao et al., 2013).

As it was predicted, the role of the number of medicines per prescription significantly affected both clinically relevant and significant DDIs as shown in logistic regression analysis. Previous studies showed that the number of medications considerably influenced the potential (Ahmadizar, Soleymani, Abdollahi, 2011; Lin, Wang, Bai, 2011) as well as the clinically relevant DDIs (Jazbar et al., 2017). However, our finding showed a higher prevalence compared to a study in Turkey in which the prevalence of DDIs was $\geq 70 \%$ in patients taking 7 or more medication using the Lexi-Interact (Gören et al., 2017).

We investigated the role of the prescriber's specialty on both clinically relevant and significant DDIs and found a significant impact. It was previously reported 
that the prescriptions by cardiologists and internists had significantly higher DDIs vs. those by dermatologists. However, in the mentioned study, the prescriptions belonged to all patient age groups and adjustment for the mean number of items in prescriptions was not performed (Ahmadizar, Soleymani, Abdollahi, 2011). At the first glance, it may seem that the finding might be due to differences in the mean number of medications per prescription in different specialties. However, a marked finding of our study was regarding the role of the prescriber even when the prescription items were adjusted in logistic regression. Thus, it is probably the nature of the medications that different prescribers prescribe that affects the DDIs rather than the number of medicines.

In the present study, analysis of potential DDIs was performed based on the Lexicomp ${ }^{\circledR}$ and interactions in the $\mathrm{X}$ category were checked against the "Drug Interaction Facts". As expected, there were disagreements between commonly used DDI detectors in listing and severity rating (Marusic et al., 2013). However, the aim of the current study was not to compare the two tools. Although utilization of several sources can minimize this potential bias (Obreli-Neto et al., 2012), the Lexi-Interact is eligible due to its high sensitivity and specificity (Marusic et al., 2013).

We found that, $16.3 \%$ of the patients received PIMs based on the Zhan criteria, which was similar to the findings of previous studies with different patient populations reporting a prevalence of $16.2-35.8 \%$ for PIMs (Barnett et al., 2006, Buck et al., 2009; Simon et al., 2005; Williams et al., 2010; Zhan et al., 2001).

We noted that the most frequently prescribed PIMs were antihistamines (chlorpheniramine followed by diphenhydramine). Additionally, the most prevalent prescribed medications based on the Zhan criteria category were dicyclomine and hyoscine equally in the first category and chlordiazepoxide and chlorpheniramine in the second and third categories, respectively. However, previous studies showed that belladonna alkaloids followed by dicyclomine and hyoscyamine were the most frequent prescribed medications in the first category, propoxyphene, cyclobenzaprine, and diazepam were frequently prescribed in the second category and amitriptyline, oxybutynin and diphenhydramine were frequently prescribed in the third category (Barnett et al., 2006; Simon et al., 2005).

Among the mentioned medications, cyclobenzaprine and propoxyphene were not available in Iran Drug List at the time of the study. Additionally, according to the Food and Drug Administration of the Islamic Republic of Iran, community pharmacies are not authorized to dispense opioid medicines and these drugs can only be obtained from the Vice Chancellor for Food and Drug of medical universities. Therefore, prescriptions only containing opioid medications were not presented to the pharmacies from which prescription samples were collected.

In a study in Iran that evaluated PIMs based on the Beers criteria in the specialists' prescriptions, the most common PIMs that were similar to the PIMs in the Zhan criteria were clidinium $\mathrm{C}$, indomethacin, chlordiazepoxide, dipyridamole, and methocarbamol (Zargarzadeh, Sadeghi, Mirmoghtadaei, 2008).

It has been proposed that the number of medications received by patients is significantly associated with increased prevalence of PIMs based on the Zhan criteria (Steinman et al., 2009). Similar findings were noted in the present study. However, no correlation with age was noted.

\section{Limitation}

This study had several limitations. First, the clinical outcomes of DDIs and PIMs were not available. Moreover, only one prescription was investigated for each patient and other data regarding simultaneous drug therapies as prescribed drugs by other physicians or over-the-counter medications were not included, which could affect the results and lead to underestimation of the PIMs and DDIs. In fact, studies that consider the complete medication list of the patients can report the medication therapy problems more precisely without this substantial limitation.

The Zhan criteria were applied to determine the PIMs in this study. Among 33 medications in these criteria, 27 medications were available in the Iran Drug List at the time of the study, of which only 25 were sold in the country based on the wholesale data of the study period. Additionally, these criteria have some inherent limitations such as lack of updates based on more recent evidence, a limited number of medications included, lack of data regarding medication dosing and duration (Pugh et al., 2005) and disease-contraindicated drugs (Goulding, 2004), which might result in underestimation of the real frequency of PIMs.

\section{CONCLUSION}

DDIs are still frequently experienced by geriatric patients and the number of items per prescription and the specialty of the prescribers are significant determinants of clinically relevant and significant interactions. Specifically, 
cardiologists, neurologists, and orthopedic surgeons need to be more aware of DDIs. As for PIMs, more attention should be paid to antihistamines as the most frequently prescribed inappropriate medication.

\section{ACKNOWLEDGMENT}

This research was supported by Tehran University of Medical Sciences (grant number: 92-02-156-23585).

\section{REFERENCES}

Ahmadizar F, Soleymani F, Abdollahi M. Study of drugdrug interactions in prescriptions of general practitioners and specialists in Iran 2007-2009. Iran J Pharm Res. 2011;10(4):921-931

Azoulay L, Zargarzadeh A, Salahshouri Z, Oraichi D, Bérard A. Inappropriate medication prescribing in communitydwelling elderly people living in Iran. Eur J Clin Pharmacol. 2005;61(12):913-919.

Barnett MJ, Perry PJ, Langstaff JD, Kaboli PJ. Comparison of rates of potentially inappropriate medication use according to the Zhan criteria for VA versus private sector medicare HMOs. J Manag Care Pharm. 2006;12(5):362-370.

Basnet S, Paudel KR, Sah AK, Jha RK, Sah P, Adhikari S, Shrestha S. Prescribing pattern, polypharmacy and potentially inappropriate prescribing in hospitalized elderly patients: a retrospective study in a teaching hospital in Nepal. Int J Sci Rep. 2016;2(1):7-12.

Bazargan M, Yazdanshenas H, Han S, Orum G. Inappropriate medication use among underserved elderly African Americans. J Aging Health. 2016;28(1):118-138.

Buck MD, Atreja A, Brunker CP, Jain A, Suh TT, Palmer RM, Dorr DA, Harris CM, Wilcox AB. Potentially inappropriate medication prescribing in outpatient practices: prevalence and patient characteristics based on electronic health records. Am J Geriatr Pharmacother. 2009;7(2):84-92.

Dirin MM, Mousavi S, Afshari AR, Tabrizian K, Ashrafi MH. Potential drug-drug interactions in prescriptions dispensed in community and hospital pharmacies in East of Iran. J Res Pharm Pract. 2014;3(3):104-107

Fadare JO, Ajayi AE, Adeoti AO, Desalu OO, Obimakinde AM, Agboola SM. Potential drug-drug interactions among elderly patients on anti-hypertensive medications in two tertiary healthcare facilities in Ekiti State, South-West Nigeria. Sahel Med J. 2016;19(1):32-37
Ghadimi H, Esmaily HM, Wahlstrom R. General practitioners' prescribing patterns for the elderly in a province of Iran. Pharmacoepidemiol Drug Saf. 2011;20(5):482-487.

Gnjidic D, Johnell K. Clinical implications from drug-drug and drug-disease interactions in older people. Clin Exp Pharmacol Physiol.2013;40(5):320-325.

Gören Z, Demirkapu Mj, Acet Ga, Cali S, Oğlu Mgi. Potential drug-drug interactions among prescriptions for elderly patients in primary health care. Turk J Med Sci. 2017;47(1):47-54.

Goulding MR. Inappropriate medication prescribing for elderly ambulatory care patients. Arch Intern Med. 2004;164(3):305-312.

Hersh LR, Beldowski K, Hajjar ER. Polypharmacy in the geriatric oncology population. Curr Oncol Rep. 2017;19(11):73.

Jazbar J, Locatelli I, Horvat N, Kos M. Clinically relevant potential drug-drug interactions among outpatients: A nationwide database study. Res Social Adm Pharm. 2018;14(6):572-580

Johnell K, Klarin I. The relationship between number of drugs and potential drug-drug interactions in the elderly. Drug Safety. 2007;30(10):911-918.

Juárez-Cedillo T, Martinez-Hernández C, HernándezConstantino A, Garcia-Cruz JC, Mariso A. Clinical Weighting of Drug-Drug Interactions in Hospitalized Elderly. Basic Clin Pharmacol Toxicol. 2016;118(4):298-305

Lao CK, Chan KK, Tou CF, Tong HHY, Chan A. Potentially inappropriate prescribing and drug-drug interactions among elderly Chinese nursing home residents in Macao. Int J Clin Pharm. 2013;35(5):805-812.

Lexicomp $^{\circledR}$ Online $^{\mathrm{TM}}$ user guide [Available from: https:// online.lexi.com/lco/help/lco-ug.pdf

Lin CF, Wang CY, Bai CH. Polypharmacy, aging and potential drug-drug interactions in outpatients in Taiwan. a retrospective computerized screening study. Drugs Aging. 2011;28(3):219-225.

Marusic S, Bacic-Vrca V, Neto PRO, Franic M, Erdeljic V, Gojo-Tomic N. Actual drug-drug interactions in elderly patients discharged from internal medicine clinic: a prospective observational study. Eur J Clin Pharmacol. 2013;69(9):1717-1724.

Nabovati E, Vakili-Arki H, Taherzadeh Z, Hasibian MR, Abu-Hanna A, Eslami S. Drug-drug interactions in inpatient and outpatient settings in Iran: a systematic review of the literature. Daru. 2014, 25;22:52. 
Nabovati E, Vakili-Arki H, Taherzadeh Z, Saberi MR, AbuHanna A, Eslami S. Incidence rate and pattern of clinically relevant potential drug-drug interactions in a large outpatient population of a developing country. Res Pharm Sci. 2016;11(3):233-242

Nabovati E, Vakili-Arki H, Taherzadeh Z, Saberi MR, AbuHanna A, Eslami S. A survey of attitudes, practices, and knowledge regarding drug-drug interactions among medical residents in Iran. Int J Clin Pharm. 2017;39(3):560-568.

Neto PRO, Nobili A, Marusic S, Pilger D, Guidoni CM, de Oliveira Baldoni A, Cruciol-Souza JM, da Cruz AN, Gaeti WP, Cuman RKN. Prevalence and predictors of potential drug-drug interactions in the elderly: a cross-sectional study in the brazilian primary public health system. J Pharm Pharm Sci. 2012;15(2):344-354.

Novaes PH, da Cruz DT, Lucchetti ALG, Leite ICG, Lucchetti G. The "iatrogenic triad": polypharmacy, drugdrug interactions, and potentially inappropriate medications in older adults. Int J Clin Pharm. 2017;39(4):818-825.

Kargar M, Atrianfar F, Rashidian A, Heidari K, Noroozian $\mathrm{M}$, Gholami Kh et al. Prescribing for geriatrics in Tehran; is it appropriate and rational?. Med J Islam Repub Iran. 2019; 33 (143). doi: $10.34171 / \mathrm{mjiri} .33 .143$.

Obreli-Neto PR, Nobili A, de Lyra Júnior DP, Pilger D, Guidoni CM, de Oliveira Baldoni A, Cruciol-Souza JM, de Carvalho Freitas AL, Tettamanti M, Gaeti WP. Incidence and predictors of adverse drug reactions caused by drug-drug interactions in elderly outpatients: a prospective cohort study. J Pharm Pharm Sci. 2012;15(2):332-343.

Pugh MJV, Fincke BG, Bierman AS, Chang BH, Rosen AK, Cunningham FE, Amuan ME, Burk ML, Berlowitz DR. Potentially inappropriate prescribing in elderly veterans: are we using the wrong drug, wrong dose, or wrong duration? J Am Geriatr Soc. 2005;53(8):1282-1289.

Reis AMM, Cassiani SHDB. Evaluation of three brands of drug interaction software for use in intensive care units. Pharm World Sci. 2010;32(6):822-828.

Rosa ASKC, Costa BP, Kapper CP, Dalmas GGS, Sbroglio LL, Andreis L, Lampert MA. Identification of inappropiate prescribing in a Geriatric outpatient clinic using the Criteria Stopp Start. Rev Bras Geriatr Gerontol. 2016;19(5):871-879.

Salwe KJ, Kalyansundaram D, Bahurupi Y. A study on polypharmacy and potential drug-drug interactions among elderly patients admitted in department of medicine of a tertiary care hospital in Puducherry. J Clin Diagn Res. 2016;10(2): 6-10
Sánchez-Fidalgo S, Guzmán-Ramos MI, Galván-Banqueri M, Bernabeu-Wittel M, Santos-Ramos B. Prevalence of drug interactions in elderly patients with multimorbidity in primary care. Int J Clin Pharm. 2017;39(2):343-353.

Scondotto G, Pojero F, Addario SP, Ferrante M, Pastorello M, Visconti M, Scondotto S, Casuccio A. The impact of polypharmacy and drug interactions among the elderly population in Western Sicily, Italy. Aging Clin Exp Res. 2018;30(1):81-87.

Secoli S-R, Figueras A, Lebrao ML, de Lima FD, Santos JLF. Risk of potential drug-drug interactions among Brazilian elderly: a population-based, cross-sectional study. Drugs Aging. 2010;27(9):759-770.

Simon SR, Chan KA, Soumerai SB, Wagner AK, Andrade SE, Feldstein AC, Lafata JE, Davis RL, Gurwitz JH. Potentially inappropriate medication use by elderly persons in US Health Maintenance Organizations, 2000-2001. J Am Geriatr Soc. 2005;53(2):227-232

Steele KM, Ruisinger JF, Bates J, Prohaska ES, Melton BL, Hipp S. Home-Based Comprehensive Medication Reviews: Pharmacist's Impact on Drug Therapy Problems in Geriatric Patients. Consult Pharm. 2016;31(10):598-605.

Steinman MA, Rosenthal GE, Landefeld CS, Bertenthal D, Kaboli PJ. Agreement between drugs-to-avoid criteria and expert assessments of problematic prescribing. Arch Intern Med. 2009;169(14):1326-1332.

Teka F, Teklay G, Ayalew E, Teshome T. Potential drugdrug interactions among elderly patients admitted to medical ward of Ayder Referral Hospital, Northern Ethiopia: a cross sectional study. BMC Res Notes. 2016;9(1):431.

Tulner LR, Frankfort SV, Gijsen GJ, van Campen JP, Koks $\mathrm{CH}$, Beijnen JH. Drug-drug interactions in a geriatric outpatient cohort: prevalence and relevance. Drugs Aging. 2008;25(4):343-355.

Welker KL, Mycyk MB. Pharmacology in the geriatric patient. Emerg Med Clin North Am. 2016;34(3):469-481.

Williams BA, Baillargeon JG, Lindquist K, Walter LC, Covinsky KE, Whitson HE, Steinman MA. Medication prescribing practices for older prisoners in the Texas prison system. Am J Public Health. 2010;100(4):756-761.

World Health Organization. Mental health and older adults. [updated December 2017. Available from: http://www.who. int/mediacentre/factsheets/fs381/en/.]

Zargarzadeh AH, Sadeghi K, Mirmoghtadaei P. Prescribing of Potentially Inappropriate Medications to Elderly People 
by Medical Specialists in Isfahan, Iran. Iranian Journal of Pharmaceutical Sciences. 2008;4(4):241-6.

Zarif-Yeganeh M, Kargar M, Rashidian A, Jafarzadeh Kohneloo A, Gholami Kh. Out of pocket payment and affordability of medication for geriatric patients in Tehran. Iran J Public Health. 2019;48(6):1124-1132.
Zhan C, Sangl J, Bierman AS, Miller MR, Friedman B, Wickizer SW, Meyer GS. Potentially inappropriate medication use in the community-dwelling elderly: findings from the 1996 Medical Expenditure Panel Survey. Jama. 2001;286(22):2823-2829.

Received for publication on $08^{\text {th }}$ September 2018 Accepted for publication on $27^{\text {th }}$ August 2019 